\title{
Liver abscesses in cattle: A review of incidence in Holsteins and of bacteriology and vaccine approaches to control in feedlot cattle ${ }^{1,2}$
}

\author{
R. G. Amachawadi and T. G. Nagaraja ${ }^{3}$ \\ Department of Diagnostic Medicine and Pathobiology, Kansas State University, Manhattan 66506-5800
}

\begin{abstract}
Liver abscesses are the primary liver abnormality of feedlot cattle at slaughter. The incidence of liver abscesses is highly variable, but generally ranges from $10 \%$ to $20 \%$. The incidence of total and the proportion of severely abscessed livers $(\mathrm{A}+)$ are greater in Holsteins fed for beef production and culled dairy cows than in beef breeds. The reason for the greater incidence of liver abscesses in Holstein steers is not known, but one of the reasons is likely because of increased days on feed. The high prevalence in cull cows is likely because no specific intervention, such as use of tylosin in the feed, is approved for use in dairy cows. Liver abscesses are generally a sequela to ruminal acidosis and rumenitis in cattle fed diets high in readily-fermentable carbohydrates and low in roughages; thus, the term "acidosis-rumenitisliver abscess complex." Liver abscesses are almost always polymicrobial infections with Gram negative anaerobes constituting the predominant flora. Almost all studies have concluded that Fusobacterium necrophorum, a ruminal bacterium, is the primary causative agent and Trueperella (formerly Arcanobacterium) pyogenes is the secondary pathogen. A limited number of studies have been done on the bacterial
\end{abstract}

flora of liver abscesses of culled dairy cows and Holstein feedlot steers. A recent study has reported on isolation of Salmonella from liver abscesses of Holstein cattle. The control of liver abscesses in feedlot cattle has depended on the use of antibiotics, particularly tylosin, in the feed combined with sound nutritional management to minimize occurrence of acidosis and subsequent rumenitis. Although there is no evidence of resistance development in F. necrophorum, the future of tylosin use as a feed additive in feedlot cattle is uncertain. Regardless, beginning January 2017, the use of tylosin in feedlot cattle for the prevention of liver abscesses will be under veterinary oversight. Although tylosin is widely used in the feedlot industry, there is considerable interest in evaluating antibiotic alternatives, such as essential oils and vaccines, to control liver abscesses. Because liver abscess is a bacterial infection and the pathogenicity and virulence factors of $F$. necrophorum have been studied widely, there have been considerable interest and efforts to develop an efficacious vaccine. The 2 antigens that have been targeted for vaccine production are leukotoxin and outer membrane proteins of F. necrophorum.

Key words: bacteriology, beef breeds, Holsteins, liver abscesses, tylosin, vaccine

\section{INTRODUCTION}

\footnotetext{
${ }^{1}$ Based on the presentation at the Beef Cattle Nutrition Symposium titled "Feeding Holstein Steers" at the Joint Annual Meeting, July 12-16, 2015, Orlando, FL, with publication sponsored by the Journal of Animal Science and the American Society of Animal Science.

${ }^{2}$ Contribution No. 16-183-J Kansas Agric. Exp. Station, Manhattan.

${ }^{3}$ Corresponding author: tnagaraj@vet.k-state.edu

Received December 29, 2015.

Accepted February 25, 2016.
}

Liver abscesses are the primary liver abnormalities of feedlot cattle recorded at the time of slaughter (Brown and Lawrence, 2010). According to the most recent National Beef Quality Audit Report, 20.9\% of livers were condemned at slaughter, and liver abscesses accounted for approximately two-thirds of liver condemnations (McKeith et al., 2012). Feeding of high-grain-based finishing diets may result in 
Table 1. Prevalence of liver abscesses in feedlot cattle and cull cows at slaughter

\begin{tabular}{|c|c|c|c|c|c|c|}
\hline \multirow{2}{*}{$\begin{array}{l}\text { Liver } \\
\text { abscesses }{ }^{4}\end{array}$} & \multicolumn{2}{|c|}{$\begin{array}{c}\text { Feedlot cattle }(n=76,191)^{1} \\
\text { Prevalence }\end{array}$} & \multicolumn{2}{|c|}{$\begin{array}{c}\text { Feedlot cattle }(n=19,229)^{2} \\
\text { Prevalence }\end{array}$} & \multicolumn{2}{|c|}{$\begin{array}{c}\text { Cull cows }(n=1,461)^{3} \\
\text { Prevalence }\end{array}$} \\
\hline & Number & Percent & Number & Percent & Number & Percent \\
\hline None & 65,802 & 86.4 & 15,278 & 79.5 & 992 & 67.9 \\
\hline Total & 10,389 & 13.6 & 3951 & 20.5 & 469 & 32.1 \\
\hline A- & 3792 & $4.9(36.5)^{5}$ & 1579 & $8.2(40.0)^{5}$ & 103 & $7.1(21.9)^{5}$ \\
\hline A & 1986 & $2.6(19.1)$ & 1495 & $7.8(37.8)$ & 95 & $6.5(20.2)$ \\
\hline $\mathrm{A}+$ & 4611 & $6.1(44.4)$ & 877 & $4.6(22.2)$ & 271 & $18.6(57.8)$ \\
\hline \multicolumn{7}{|c|}{${ }^{1}$ Adapted from Brown and Lawrence (2010). Data were collected in years 1998 to 2009.} \\
\hline \multicolumn{7}{|c|}{${ }^{2}$ Adapted from Rezac et al. (2014b). Data collected at commercial packing plants in Kansas and Texas. } \\
\hline \multicolumn{7}{|c|}{${ }^{3}$ Adapted from Rezac et al. (2014a). Data collected at a commercial packing plant in the Great Lakes region. } \\
\hline \multicolumn{7}{|c|}{${ }^{4}$ Normal $=$ Liver free from abscesses; A- $=$ Liver with 1 to 2 small abscesses; $\mathrm{A}=$ Liver with 2 to 4 large abscesses or multiple small abscesses; $\mathrm{A}+=$} \\
\hline \multicolumn{7}{|c|}{ Liver with multiple large abscesses, abscesses adhered to diaphragm, abdominal organs or both, or open or ruptured abscesses. } \\
\hline
\end{tabular}

chronic acidosis and rumenitis, which predispose cattle to the development of liver abscesses (Brent, 1976; Nagaraja and Chengappa, 1998). Although liver abscesses are primarily a problem of feedlot cattle, they have been reported in dairy cows (Nagaraja, 2000; Doré et al., 2007), other ruminants (Santa Rosa et al., 1989; Tehrani et al., 2012), camelids (Aljameel et al., 2014), and even in monogastric animals (Rumbaugh et al., 1978; Zicker et al., 1990; Sellon et al., 2000). Liver abscesses have a significant economic impact in the feedlot cattle industry, and the impact is highly dependent on the severity of liver abscesses. Based on the number and size of abscesses, liver abscesses are scored on a scale of 1 to 3 , or as A-, A, and A+ (mild to severe, respectively), traditionally referred to as the Elanco Scoring System (Brown et al., 1975). Generally, liver abscesses with a score of A- (1) or A (2) do not have a measurable effect on cattle performance and carcass attributes (Brink et al., 1990; Davies et al., 2007; Brown and Lawrence, 2010). In a study on the association of liver abscesses with cattle performance, carcass grading, and value, Brown and Lawrence (2010) have shown that the greatest impact was in cattle with A+ liver abscesses, particularly those that had adhesions to the diaphragm or abdominal organs. The objectives of this review are to provide an update on liver abscesses in cattle with emphasis on incidence in dairy cows and in Holstein steers fed for beef production, and on bacteriology and vaccine approaches to control liver abscesses in feedlot cattle.

\section{INCIDENCE}

The incidence of liver abscesses is highly variable, ranges from a low of $0 \%$ to $1 \%$ or $2 \%$ to a high of $60 \%$ to $80 \%$, and in recent years, the incidence has ranged from $10 \%$ to $20 \%$ (Table 1; Brown and Lawrence, 2010; Rezac et al., 2014a). The incidence is in- fluenced by a number of factors such as diet (amount of forage, forage type, grain type), days on feed, cattle type (feedlot cattle or dairy cows), breed (beef breeds vs. Holsteins), gender (steers vs. heifers), geographic location, and season (Nagaraja et al., 1996b; Reinhardt and Hubbert, 2015). Elanco Animal Health (Greenfield, IN) has been collecting annual incidence of liver abscesses in major packing plants for the past several years as a part of customer service to support feed yards in managing liver abscesses. The average annual incidence of total liver abscesses in the past 10 yr (2004 to 2014) in Elanco-checked cattle by gender and cattle type (beef heifers and steers and Holstein steers) are shown in Fig. 1. The data have consistently shown that the incidence of liver abscesses is greater in steers than heifers among beef breeds and greater in Holsteins fed for beef production than beef breeds. A 10-yr average of liver abscesses in Elanco-checked cattle is $13.9 \%, 16.0 \%$, and $28.3 \%$ in beef heifers, beef steers and Holsteins, respectively. A slightly greater incidence of liver abscesses (1\% to 3\%) in steers than heifers of beef breeds is believed to be related to feed intake. Steers generally consume more DM (1\% to $3 \%$ ) than do heifers, and heifers tend to mature and finish earlier than do steers of comparable BW (DeHaan et al., 1995). Over the past 5 to $6 \mathrm{yr}$, a slight increase in the incidence of liver abscesses in beef breeds and a trend for a more pronounced increase in Holstein steers were observed (Fig. 1). The reason for the increased trend is not known.

\section{Liver Abscesses in Feedlot Holstein Steers}

In the U.S., it has become increasingly common to raise Holstein bull calves for entry into the feedlot production systems. Generally, Holstein bull calves are separated from their dams after 1 or 2 feedings of colostrum and raised in hutches at calf ranches, which 




Figure 1. A 10-yr average incidence of total abscesses in beef heifers, beef steers, and Holstein steers (Elanco Liver-Check Service, 2015).

makes preparation for entry into the feedlot markedly different from that of conventional beef breed calves (Maas and Robinson, 2007). Liver abscess data collected by the Elanco Liver Check System have shown that the incidence of liver abscesses in Holstein feedlot steers varies in different regions of the U.S. Holstein steers from feedlots in the Central and Northern Plains have a greater incidence than steers from feedlots in the Midwest, Northwest, and Southwest (Reinhardt and Hubbert, 2015). Interestingly, of the total abscesses, the proportion of $\mathrm{A}+$ abscesses and abscesses with adhesions to diaphragm and visceral organs is greater in Holstein feedlot steers than in beef breeds $(50 \%$ to $60 \%$ vs. $30 \%$ to $40 \%$ of the total abscesses, respectively). Because of greater incidence of $\mathrm{A}+$ abscesses, the impact of liver abscesses on cattle performance and carcass yield, grade, and value is likely to be greater in Holsteins compared with beef breeds. However, there has been no study published on the comparative impact of liver abscesses on cattle performance in Holstein feedlot steers. The reason for the greater incidence of liver abscesses in Holsteins is not known, but the most obvious reason given is increased days on a high- energy diet (300 to $400 \mathrm{~d}$ in Holsteins compared with 120 to 150 d in beef breeds; Vogel and Parrott, 1994; Duff and McMurphy, 2007). Also, Holstein steers have a greater daily or total feed intake (on an average, up to $12 \%$ greater) than beef breeds (Hicks et al., 1994). The greater intake is attributed to a high maintenance energy demand because of a greater proportion of gut and organ tissue. Holsteins have a larger body frame because of genetic selection for high milk production (Nagaraja et al., 1996b). However, days on feed or greater feed intake does not explain the regional differences in the incidence of liver abscesses in Holsteins. Holstein steers raised in feedlots have been observed to have habits and behavior different than that of beef breeds but much of these are anecdotal and not well documented. Eng (2005) outlined the following features of Holsteins that are different from beef breeds: 1) Holsteins are easily bored and, therefore, may groom more and sort feed; 2) Holsteins have greater death loss and higher incidence of metabolic diseases, such as acidosis and bloat; and 3) Holstein pens are wetter because of greater water intake and urination. 
It is possible that the differences in behavior or feeding habits (sorting of feed, grooming, wetter pens) could be contributing factors for the greater incidence of liver abscesses. For example, Holsteins have a tendency to groom more than beef breeds, which may increase ingestion of hide hair. Penetration of hair into the ruminal wall may pave a path for bacterial entry to cause ruminal abscesses. The difference in hair structure between cattle and sheep is often cited as the reason for the low prevalence of rumenitis in grain-fed sheep compared with cattle (Fell et al., 1972). Fell et al. (1972) also reported that inclusion of cattle hair in high-grain diets fed to sheep resulted in an increase in the prevalence of rumenitis and liver abscesses. Another theory for greater incidence, particularly of the increased severity ( $\mathrm{A}+$ abscesses), is that the bacterial flora, qualitatively or virulently, of liver abscesses of Holsteins may be different from that of beef breeds. Again, there has been no published study that has compared the flora of liver abscesses between Holsteins and beef breeds.

\section{Liver Abscesses in Dairy Cows}

Dairy cows are predisposed to ruminal acidosis and subsequent rumenitis because of increased intake of energy-dense diets and rapid dietary changes associated with pregnancy and lactation. Generally, cows are switched from high-forage diets prepartum to a high-energy, low forage diet postpartum to meet energy demands of lactation. The change often includes a switch from hay to silage or pelleted forages. Lactating cows are more prone to subacute or subclinical ruminal acidosis during the first 30 to $35 \mathrm{~d}$ of lactation, but ruminal damage happens more gradually and is due to increased ruminal concentration of VFA (Dirksen et al., 1985; Plaizier et al., 2008). Doré et al. (2007) reported on clinical findings of liver abscesses in 18 Holstein cows collected over a 12-yr period in a veterinary teaching hospital. Abscesses were diagnosed by either ultrasound examination or during an exploratory laparotomy. Liver abscesses were associated with other diseases such as peritonitis, vagal indigestion, traumatic reticuloperitonitis, abomasal displacement, pneumonia, and enteritis. Most of the information on the incidence in dairy cows is based on the data collected from slaughtered culled cows originating from dairies. The culling of cows that are no longer productive is a widely practiced strategy in dairies, and sale and slaughter of such cows contribute significantly to the beef supply. In 2014, dairy cows accounted for $9.5 \%$ of the total cattle slaughtered in USDA-inspected slaughter houses (USDA, 2015). Rezac et al. (2014b) have reported on the prevalence and severity of liver abscesses in culled dairy and beef cows that originated from the Great Lakes and northern Midwest regions of the U.S. Of the 1461 cows examined at slaughter, over the course of 3 visits to an abattoir, $87 \%$ were classified as Holsteins and more likely to have originated from dairy farms. Thirty-two percent of cows $(469 / 1,461)$ were observed to have abscesses in the liver and over one-half of those with liver abscesses (58\% of the total) were categorized as $\mathrm{A}+$ (Table 1$)$ and a vast majority of those $(90 \%)$ were observed with at least one abscess adhered to the diaphragm, abdominal wall, or other visceral organs. The increased prevalence of total and A+ liver abscesses in cull cows compared with feedlot cattle is likely because no specific interventions, such as use of tylosin in the feed, that control of target liver abscesses are available for use in dairy cows.

\section{PATHOGENESIS}

Liver abscesses are considered generally as a sequelae to ruminal acidosis and rumenitis in cattle fed diets high in readily-fermentable carbohydrates and low in roughages, thus, the term "acidosis-rumenitisliver abscess complex." The first observation of a relationship between liver abscesses and ruminal lesions in feedlot cattle was made by Smith (1944), which was later confirmed by Jensen et al. (1954). In a recent study on the relationship between rumen health scores and liver abscesses in beef cattle at slaughter, Rezac et al. (2014a) observed that $32 \%$ of cattle with mild or severe rumenitis had liver abscesses compared with $19 \%$ of cattle with healthy ruminal walls. However, not all studies have shown an association of liver abscesses with ruminal lesions (Wieser et al., 1966). Acid-induced rumenitis and damage of the protective surface usually are associated with a sudden change to high-energy diets and other dietary indiscretions, such as a change in feeding patterns, letting cattle become overly hungry, feeding unpalatable diets, and feeding very little roughage or penetration of foreign objects (Elam, 1976). Because Holstein feedlot steers are on a high-grain and low-roughage diet for an extended period of time $(>300 \mathrm{~d})$, they are likely to have greater incidence of rumenitis, which could explain the greater incidence of liver abscesses. However, there has been no published study on the incidence of rumenitis and comparative appearance and pathology of ruminal epithelium between Holstein feedlot steers and beef breeds. A recent study (Rezac et al., 2014b) on gross pathologic conditions in cull cows at slaughter showed that $64.8 \%$ of rumens examined had normal appearance and papillary structure, whereas the remaining had mild $(25.1 \%)$ to severe rumenitis $(10 \%)$. 
The most common ruminal lesions were parakeratosis, blunted papillae or denuded areas of epithelium, and in more severe cases, ulceration and scar tissue formation (Rezac et al., 2014b).

Other portals of entry of bacteria into the liver parenchyma to set up infection include hepatic artery, the umbilical vein (in neonatal calves), and the biliary tree (Kelly, 1993). In dairy cows, traumatic reticuloperitonitis, caused by sharp metallic objects lodged in the reticulum and perforating through the reticular wall, is often a predisposing factor for liver abscesses. Local peritonitis resulting from bacterial entry through perforated epithelium could extend into the liver to set up abscesses. Because dairy cows usually reach an older age than feedlot cattle and are fed in a confined area as compared with pasture grazing, there is an increased chance of these animals experiencing traumatic reticuloperitonitis (Grohn and Bruss, 1989). Occasionally, caudal vena caval thrombosis can be caused by the erosion of hepatic abscesses into the caudal vena cava causing sudden death in cattle (Rebhun et al., 1980). In most cases, varying degrees of pulmonary artery thrombosis, pulmonary infarction, suppurative pneumonia, congestive right heart failure, endocarditis, hemoptysis, and epistaxis may occur, resulting in what is commonly known as "caudal vena caval thrombosis syndrome" (Gudmundson et al., 1980).

\section{BACTERIOLOGY}

Liver abscesses are almost always polymicrobial infections with Gram negative anaerobes constituting the predominant flora (Scanlan and Hathock, 1983; Nagaraja and Chengappa, 1998). Almost all studies have concluded that Fusobacterium necrophorum is the primary causative agent. The second most frequently isolated pathogen is Arcanobacterium pyogenes (Scanlan and Hathock, 1983; Lechtenberg et al., 1988). The organism is now named Trueperella pyogenes because, phylogenetically, the genus Arcanobacterium consisted of 2 distinct groups that differed in 16S rRNA signature nucleotide sequences and menaquinone and phospholipid compositions (Yassin et al., 2011). The A. pyogenes group was placed as members of a new genus Trueperella (named after Hans Georg Trüper, a German microbiologist). Additionally, a number of other anaerobic and facultative bacteria including Bacteriodes spp., Clostridium spp., Escherichia coli, Klebsiella spp., Enterobacter spp., Mobilincus spp., Pasteurella spp., Peptostreptococcus spp., Porphyromonas spp., Prevotella spp., Propionibacterium spp., Staphylococcus spp., Streptococcus spp., and many unidentified Gram-negative and Gram-positive bacteria have been isolated from
Table 2. Bacterial species isolated from liver abscesses in cull cows collected at slaughter ${ }^{1}$

\begin{tabular}{lcc}
\hline \hline & \multicolumn{2}{c}{ Liver abscesses from cows with: } \\
\cline { 2 - 3 } & $\begin{array}{c}\text { Acidosis and } \\
\text { rumenitis } \\
(n=28)\end{array}$ & $\begin{array}{c}\text { Reticuloperitonitis } \\
(n=29)\end{array}$ \\
Bacterial species & 20 & 29 \\
\hline Fusobacterium necrophorum & 13 & 26 \\
Subsp. necrophorum & 8 & 9 \\
Subsp. funduliforme & 15 & 11 \\
Trueperella pyogenes & 5 & 2 \\
Clostridium perfringens & & \\
\hline
\end{tabular}

${ }^{1}$ Adapted from Purvis (2006).

${ }^{2}$ Liver abscesses from cows with no evidence of reticuloperitonitis, hence, assumed to have originated of ruminal acidosis and rumentis.

${ }^{3}$ Liver abscesses from cows with evidence of reticular perforation.

liver abscesses of feedlot cattle (Scanlan and Hathock, 1983; Nagaraja and Chengappa, 1998; Nagaraja and Lechtenberg, 2007).

A limited number of studies have been done on the bacterial flora of liver abscesses of dairy or cull cows and Holstein feedlot steers. Purvis (2006) has reported on the bacterial flora of liver abscesses collected from culled dairy cows at slaughter. Fifty-seven livers with abscesses were collected from a slaughter house in Pennsylvania over a period of 15 wk from July 2000 to October 2000. Twenty-nine abscesses were from cows with reticuloperitonitis based on obvious signs of puncture in the reticulum, and 28 abscesses with no evidence of reticuloperitonitis were assumed to have originated because of ruminal acidosis and subsequent rumenitis. In both types of abscesses, $F$. necrophorum and $T$. pyogenes were the primary and secondary pathogens, respectively (Table 2). Doré et al. (2007) reported on bacterial isolations from the pus collected from abscesses of 11 of 18 Holstein cows that were diagnosed by ultrasonography or exploratory laparotomy in the veterinary clinic. Only aerobic culture was done from 2 abscesses and both yielded no growth. Both aerobic and anaerobic isolations were done from 9 abscesses. Anaerobic bacteria were obtained from 7 samples and included $F$. necrophorum $(n=2)$, Bacteroides spp. $(n=2)$, Peptococcus spp. $(n$ $=1)$, Peptostreptococcus spp. $(n=1)$, and unidentified Gram-positive cocci $(n=1)$. The most common aerobic bacteria isolated was $T$. pyogenes $(n=4)$.

In a recent study, 10 liver abscess samples collected at slaughter from Holstein steers that originated from a single feedlot in the Midwest were subjected to anaerobic and aerobic bacterial isolations (Amachawadi and Nagaraja, 2015). Fusobacterium necrophorum was isolated from all ten abscesses (100\%) and $T$. pyogenes was isolated from 4 abscesses (40\%). Interestingly, Salmonella enterica was also isolated 




\section{Source}

Liver abscess

Liver abscess

Liver abscess

Liver abscess

Liver abscess

Liver abscess

Liver abscess

Liver abscess

Liver abscess

Liver abscess

Lymph node

Lymph node

Figure 2. Pulsed-field gel electrophoresis binding patterns of restriction endonuclease Xba1-digested Salmonella enterica strains isolated from liver abscesses of Holstein feedlot steers (Amachawadi and Nagaraja, 2015) and from lymph nodes of cattle at slaughter (Bugarel et al., 2015).

from all 10 samples from inoculated blood agar plates that were incubated anaerobically. This was the first report on the isolation of Salmonella enterica from liver abscesses of cattle. However, there are reports of Salmonella isolation from liver abscesses in humans (Chaudhry et al., 2003; Qu et al., 2013). Isolation of Salmonella by anaerobic culture method is not surprising because it is well known that Salmonella are capable of robust growth under anaerobic conditions (Yamamoto and Droffner, 1985). In fact, Salmonella grown anaerobically was more invasive and virulent, and adhered better to mammalian cells compared with aerobically-grown cells (Lee and Falkow, 1990; Schiemann and Shope, 1991). Serotyping done by the National Veterinary Services Laboratories (Ames, IA) identified the liver abscess strains as $S$. enterica subsp. enterica 6,7:g,m,s:e,n,z15, a novel serotype. The antigenic designation of the 10 liver abscess strains was exactly same as the 2 novel strains of Salmonella, isolated from lymph nodes of slaughtered cattle (Gragg et al., 2013). The novel serotype is now named Lubbock, and has been shown to be closely related to the serotype Mbandaka (Bugarel et al., 2015). Interestingly, the pulsed-field gel electrophoresis (PFGE) banding patterns of the 2 Lubbock strains from lymph nodes were $100 \%$ identical to the banding patterns of the 10 liver abscess strains (Fig. 2); however, the identical banding pattern may not necessarily mean that the lymph node strains are related to liver abscess strains. Although PFGE is routinely used to assess strain relatedness in outbreak investigations of food-borne pathogens, in the case of Salmonella, at least with some serotypes, PFGE has proven to be serotype-specific and not strain-specific (Zou et al., 2010). It is not known whether $S$. enterica is one of the etiologic agents or a secondary invader into an abscess initiated by $F$. necrophorum, via lymph or blood, and survived. The plausible hypothesis is that Salmonella present in the gut could cross the gut epithelial barrier, most likely in the small or large intestine, to gain access via lymph to the portal circulation, and get filtered by the portal capillary system of the liver to initiate infection. Further studies are needed to determine the prevalence and importance of Salmonella in liver abscesses of cattle.

\section{Fusobacterium necrophorum}

Fusobacterium necrophorum, identified as an animal and human pathogen in the late 1880 s, is a Gramnegative, rod-shaped, or pleomorphic bacterium (Langworth, 1977). The bacterium is an aerotolerant anaerobe (Tan et al., 1992). Fusobacterium necrophorum has also been identified as the primary pathogen in necrotic laryngitis (calf diphtheria) and in foot rot and foot abscesses in cattle (Emery et al., 1985; Tan et al., 1996). The organism is also considered to be one of the primary pathogens associated with uterine diseases (puerperal metritis and endometritis) in dairy cows (Bicalho et al., 2012). In humans, F. necrophorum causes sore throat (pharyngitis) and tonsillitis, more often in young adults (Ludlam et al., 2009), which in rare occasions leads to a complication called Lamierre's syndrome (Kuppalli et al., 2012). In fact, fusobacterial infection of the throat is considered to be second only to group A streptococci (Amess et al., 2007). A draft genome sequence of a liver abscess isolate of $F$. necrophorum has been published (Calcutt et al., 2014). The genome size is $2.09 \mathrm{Mb}$, which is within the range (1.96 to 2.3) reported for human strains of F. necrophorum. Annotation of the sequence identified 1990 genes, including 1907 open reading frames, 48 tRNA, and 20 rRNA (Calcutt et al., 2014).

Fusobacterium necrophorum is part of the normal gastrointestinal, respiratory, and urogenital flora of 
animals and humans, as well as a soil bacterium. The organism is a normal inhabitant of the rumen, and its fermentative role is to utilize lactic acid to produce VFA and breakdown feed and rumen epithelial proteins and amino acids. The organism is also considered to be a major lysine degrading bacterium in the rumen (Russell, 2006; Elwakeel et al., 2013). Ruminal concentration of $F$. necrophorum is low $\left(<10^{6}\right)$, but is greater in cattle fed grain-based diets compared with roughage-based diets (Tan et al., 1994). This is likely to be due to increased lactate availability from the high-grain diet. Therefore, conditions that lead to lactate accumulation, such as acute acidosis, should promote proliferation of $F$. necrophorum. Because lactate accumulation decreases ruminal $\mathrm{pH}(<5.5)$, fusobacterial growth is inhibited (Coe et al., 1999). Despite this, ruminal acidity remains a predisposing factor because the ruminal wall is more likely to permit entry and colonization by $F$. necrophorum after acid-damage. Fusobacterium necrophorum also forms a part of the flora that adheres to the ruminal wall because of its aerotolerance and ability to grow at physiological $\mathrm{pH}$. The adhesion has been shown to be mediated by outer membrane proteins (Kumar et al., 2013). Kanoe et al. (1978) have reported on isolation of F. necrophorum from ruminal walls of cattle exhibiting parakeratosis and rumenitis (Table 3 ).

There are 2 subspecies of $F$. necrophorum, subsp. necrophorum and subsp. funduliforme (Shinjo et al., 1991). These 2 subspecies differ in cell morphology, colony characteristics, growth patterns in broth, and most importantly, in the production of virulence factors (Tadepalli et al., 2009). Subspecies necrophorum is more virulent and, thus, more frequently encountered in liver abscesses than subsp. funduliforme, which tends to occur more often in mixed infections (Lechtenberg et al., 1988). Interestingly, the human clinical strains are clearly distinct from subsp. necrophorum of cattle origin, and are more similar to subsp. funduliforme (Hall et al., 1997; Tadepalli et al., 2008). The difference in virulence correlates with the difference in virulence factors between the 2 subspecies, with leukotoxin being the major virulence factor involved in the infection (Emery and Vaughan, 1986; Tan et al., 1996; Narayanan et al., 2003; Nagaraja et al., 2005). Leukotoxin is an exotoxin, composed of protein that is cytotoxic to neutrophils, macrophages, hepatocytes, and possibly to ruminal epithelial cells (Narayanan et al., 2002). Subsp. necrophorum produces more leukotoxin than funduliforme (Coyle-Dennis and Lauerman, 1979; Emery et al., 1985; Tan et al., 1992), and isolates from liver abscesses tend to be more leukotoxic than isolates from the rumen, indicating a selective advantage for high-leukotoxin-producing strains to survive
Table 3. Association of Fusobacterium necrophorum and Trueperella pyogenes liver abscess isolates with ruminal wall and ruminal contents

\begin{tabular}{|c|c|c|c|c|c|c|}
\hline \multirow[b]{3}{*}{ Location } & \multicolumn{3}{|c|}{$\begin{array}{c}\text { Fusobacterium } \\
\text { necrophorum }^{1}\end{array}$} & \multicolumn{3}{|c|}{$\begin{array}{l}\text { Trueperella } \\
\text { pyogenes }^{2}\end{array}$} \\
\hline & \multirow{2}{*}{$\begin{array}{c}\text { No. of } \\
\text { samples } \\
\text { tested }\end{array}$} & \multicolumn{2}{|c|}{ Positive } & \multirow{2}{*}{$\begin{array}{c}\text { No. of } \\
\text { samples } \\
\text { tested }\end{array}$} & \multicolumn{2}{|c|}{ Positive } \\
\hline & & Number & Percent & & Number & Percent \\
\hline $\begin{array}{l}\text { Ruminal } \\
\text { wall }\end{array}$ & 50 & 22 & 44 & 59 & 45 & 76.2 \\
\hline $\begin{array}{l}\text { Ruminal } \\
\text { contents }\end{array}$ & 101 & 59 & 58.4 & 59 & 17 & 28.8 \\
\hline
\end{tabular}

${ }^{1}$ Adapted from Kanoe et al. (1978).

${ }^{2}$ Adapted from Narayanan et al. (1998).

in the ruminal epithelium and in the liver parenchymal tissue (Tan et al., 1994). Leukotoxin is encoded by a gene designated as $l k t A$, which is the second gene in a 3-gene operon of $l k t B, l k t A$, and $l k t C(\mathrm{Na}-$ rayanan et al., 2001). The $l k t A$ leukotoxin gene ORF is $9726 \mathrm{bp}$, encoding a protein of 3,241 amino acids with a molecular weight of $336,956 \mathrm{da}$. The toxin is considerably greater in molecular weight than leukotoxins produced by other bacteria and has no significant sequence similarity to any other bacterial toxins described (Narayanan et al., 2002). The LktB protein of the $l k t B$ is believed to be involved in the secretion of the leukotoxin by $F$. necrophorum. The biological function of the LktC protein has not been determined. The subsp. funduliforme lkt operon is organized identically to the subsp. necrophorum operon. Although the overall sequence similarity of the Lkt proteins is high between the 2 subspecies ( $87 \%$ and $88 \%$, respectively), the LktA and LktB proteins have significant differences in their N-terminal sequences (Tadepalli et al., 2009). The decreased production of leukotoxin by subsp. funduliforme appears to be because of weak promoter activity compared with subsp. necrophorum (Zhang et al., 2006). The importance of leukotoxin as a virulence factor is indicated by the correlation between toxin production and abscess formation in laboratory animals (Coyle-Dennis and Lauerman, 1979), inability of nonleukotoxin-producing strains to cause foot abscesses (Emery et al., 1985), and a relationship between antileukotoxin antibody titers and protection against infection (Saginala et al., 1997).

\section{Trueperella pyogenes}

Trueperella pyogenes is a Gram-positive, rodshaped, and facultatively-anaerobic organism, which is frequently isolated as a single or mixed culture from a variety of pyogenic infections in animals (Nagaraja, 2013; Ribeiro et al., 2015). The organism exists as a 
Table 4. Induction of liver abscesses in steers by intraportal inoculation of Trueperella pyogenes alone or in combination with Fusobacterium necrophorum ${ }^{1}$

\begin{tabular}{|c|c|c|c|c|c|c|}
\hline \multirow[b]{2}{*}{ Treatment groups } & \multirow[b]{2}{*}{ Dose inoculated } & \multirow[b]{2}{*}{$\begin{array}{l}\text { No. of } \\
\text { steers }\end{array}$} & \multicolumn{2}{|c|}{$\begin{array}{l}\text { No. of steers with } \\
\text { liver abscesses detected }\end{array}$} & \multicolumn{2}{|c|}{ Bacterial isolation } \\
\hline & & & $\begin{array}{c}\text { By } \\
\text { ultrasonography } \\
\text { on d } 14\end{array}$ & $\begin{array}{c}\text { At } \\
\text { necropsy } \\
\text { on d } 14\end{array}$ & F. necrophorum & T. pyogenes \\
\hline F. necrophorum & $5 \mathrm{~mL}$ of $2.4 \times 10^{7}$ & 5 & $5^{2}$ & 4 & 4 & 0 \\
\hline T. pyogenes & $10 \mathrm{~mL}$ of $2.0 \times 10^{8}$ & 5 & 0 & 0 & 0 & $4^{3}$ \\
\hline T. pyogenes $+F$. necrophorum & $\begin{array}{l}2.5 \mathrm{~mL} \text { of } 2.0 \times 10^{8} \text { plus } 2.5 \mathrm{~mL} \\
\text { of } 2.4 \times 10^{7} \text { of } \text { F. necrophorum }\end{array}$ & 5 & 0 & 0 & 0 & 0 \\
\hline $\begin{array}{l}\text { T. pyogenes }+ \text { leukotoxin of } \\
\text { F. necrophorum }\end{array}$ & $\begin{array}{l}2.0 \times 10^{9} \text { plus } 10 \mathrm{~mL} \text { of culture } \\
\text { supernatant from } F . \text { necrophorum }\end{array}$ & 5 & $3^{4}$ & 2 & 0 & 2 \\
\hline
\end{tabular}

commensal on mucous membranes of the upper respiratory and digestive tracts of animals (Biberstein, 1990). The source of $T$. pyogenes in liver abscesses appears to be the ruminal wall and is more frequently isolated from the ruminal wall than the contents (Table 3; Narayanan et al., 1998). Because it is a facultative anaerobe, its niche is more likely to be the ruminal wall where oxygen is available from the blood circulation in an otherwise anaerobic environment of the rumen. Trueperella pyogenes is the second most frequently isolated pathogen in liver abscesses (Tan et al., 1996). The frequent association of $T$. pyogenes with $F$. necrophorum, not only in liver abscesses, but also in foot rot and abscesses in cattle (Nagaraja et al., 2005) and metritis in dairy cows (Bicalho et al., 2012), is because of the nutritional and pathogenic synergy between the 2 species (Tadepalli et al., 2009). Generally, the occurrence of T. pyogenes is around $2 \%$ to $20 \%$ of liver abscesses (Nagaraja et al., 1996a). However, in certain situations, the prevalence of $T$. pyogenes in liver abscesses is greater. For example, in liver abscesses that occur in cattle that received tylosin in the feed, the prevalence of $T$. pyogenes was 53\% compared with only $10 \%$ in liver abscesses of cattle originating from feed yards that traditionally do not feed tylosin (Nagaraja et al., 1999). The greater prevalence of $T$. pyogenes in liver abscesses of tylosin-fed cattle is somewhat surprising because the organism, being Gram positive, is susceptible to tylosin and also to monensin, an ionophore that is often included with tylosin (Tan et al., 1994). Possibly, the association of T. pyogenes with the ruminal wall prevents exposure to inhibitory concentrations of tylosin and monensin (Nagaraja et al., 1999). Additionally, liver abscesses of cull dairy cows have a high prevalence of $T$. pyogenes compared with feedlot cattle (Table 2; Purvis, 2006). The greater prevalence of $T$. pyogenes in liver abscesses may be related to the extent of ruminal damage and lesions. This may be related to damage caused to the rumen by lack of roughage or high acidity; greater damage increases the likelihood of $T$. pyogenes entering into the portal circulation to reach the liver. In rare instances, $T$. pyogenes is the only organism isolated (Nagaraja and Lechtenberg, 2007) from liver abscesses, which raises the question of whether the organism alone could cause liver abscesses. In a study reported in a Scientific Update on Rumensin and Tylan (Lechtenberg et al., 1993), steers inoculated intraportally, via ultrasoundguided, percutaneous catheter, with $T$. pyogenes in pure culture did not develop abscesses. However, in combination with $F$. necrophorum culture supernatant steers developed liver abscesses suggesting that possibly leukotoxin is necessary for $T$. pyogenes to survive in the liver and contribute to the development of abscesses (Table 4). The principal virulence factor of $T$. pyogenes is a hemolysin, called pyolysin, which is also cytotoxic to polymorphonuclear cells (Billington et al., 1997). Other virulence factors such as proteases, DNases, neuraminidases, and extracellular matrixbinding protein are involved in the adherence, colonization, and pathogenicity (Jost and Billington, 2005).

\section{CONTROL}

The control of liver abscesses in feedlot cattle has largely depended on the use of antimicrobial compounds in the feed combined with prudent nutritional management to minimize occurrence of ruminal acidosis and subsequent rumenitis. Based on the Feed Additive Compendium, 6 antibiotics (bacitracin methylene disalicylate, chlortetracycline, neomycin sulfate in combination with oxytetracycline, oxytetracycline, tylosin, and virginiamycin) are approved for the prevention of liver abscesses in feedlot cattle 
(Lundeen, 2013). These antibiotics vary in their inhibitory effects on $F$. necrophorum and A. pyogenes and their effectiveness in preventing liver abscesses (Nagaraja and Chengappa, 1998). Tylosin, a macrolide, is the most effective antibiotic and the most commonly used feed additive ( 8 to $10 \mathrm{~g} /$ ton to provide 60 to $90 \mathrm{mg} \cdot$ animal $^{-1} \cdot \mathrm{d}^{-1}$ ) in the feedlot. The mode of action of tylosin is believed to be its inhibitory effect on F. necrophorum in the rumen, in the liver, or both (Nagaraja and Lechtenberg, 2007). A meta-analysis on liver abscess risks of cattle receiving tylosin vs. cattle not receiving tylosin in conventional feeding systems showed that the feeding of tylosin reduced the risk of liver abscesses from $30 \%$ to $8 \%$ (Wileman et al., 2009). The incidence of liver abscesses in tylosin-fed cattle may be because of the development of resistance in $F$. necrophorum or abscesses caused by bacteria other than F. necrophorum. In a study that compared the antimicrobial susceptibilities of bacterial isolates between liver abscesses of cattle that originated from feed yards that fed tylosin or no tylosin, the mean minimum inhibitory concentrations of tylosin to $F$. necrophorum and $T$. pyogenes did not differ between the 2 groups (Nagaraja et al., 1999).

Although there is no evidence of resistance development in $F$. necrophorum, the future of tylosin use as a feed additive in feedlot cattle is uncertain. In April 2012, the Center for Veterinary Medicine of the US Food and Drug Administration issued a document titled "The Judicious Use of Medically Important Antimicrobial Drugs in Food Producing Animals" (FDA, 2012) that provided nonbinding recommendations, based on 2 principles: 1) limit medically-important antimicrobial drugs to uses in animals that are considered necessary for assuring animal health, and 2) limit medically-important antimicrobial drugs to use in animals that include veterinary oversight or consultation. Therefore, because of the risk that antimicrobial resistance poses to public health, the use of medicallyimportant antimicrobial drugs for production purposes in food animals does not represent a judicious use of these drugs. In contrast, the guidance suggests that antibiotics for the treatment, control, and prevention of specific diseases to be therapeutic uses, which are necessary for assuring the health of food animals. Because tylosin is used to prevent liver abscesses and not intended for growth promotion, it could be categorized as use to assure animal health. Regardless, beginning January 2017, the use of tylosin in feedlot cattle for the prevention of liver abscesses will be under veterinary oversight (FDA, 2013).

Although tylosin is widely used in the feedlot industry, there is considerable interest in evaluating antibiotic alternatives, such as essential oils and vac- cines, to control liver abscesses. Elwakeel et al. (2013) evaluated 5 essential oils (eugenol, vanillin, thymol, guaiacol, and limonene) and of a commercial product, CRINA (DSM Nutritional Products, Parsipanny, NJ) on the growth of $F$. necrophorum and observed that limonene, at 20 or $100 \mu \mathrm{g} / \mathrm{mL}$, and thymol, at $100 \mu \mathrm{g} /$ $\mathrm{mL}$, inhibited $F$. necrophorum growth, whereas eugenol, guaiacol, vanillin, and CRINA had no effect. The failure of CRINA to inhibit $F$. necrophorum was likely because of low concentrations of limonene and thymol in the product. The antimicrobial activity of essential oils is attributed to the disruption of the cytoplasmic membrane of the bacterial cells (Nazzaro et al., 2013). In a feedlot study in cattle fed a finishing diet, inclusion of CRINA containing limonene and thymol tended to reduce the incidence of liver abscesses compared with the control, but the difference was not significant (Meyer et al., 2009).

\section{Vaccine Approach}

Because liver abscess is a bacterial infection and the pathogenicity and virulence factors of F. necrophorum have been studied widely for many years, there has been considerable interest and efforts to develop an effective vaccine (Nagaraja and Chengappa, 1998). The use of vaccines has dual benefits; control of liver abscesses and alleviation of public health concerns associated with the continuous use of medically-important antimicrobials in feed. Thus far, 2 vaccines have reached commercial application. One was a $F$. necrophorum bacterin (Fusogard, Elanco Animal Health) approved for the control of liver abscesses and foot rot in cattle. The second vaccine (marketed as Centurion by Merck Animal Health, Omaha, NE) was a combination of leukotoxoid of F. necrophorum and a T. pyogene bacterin, which was shown to reduce the prevalence of liver abscesses in feedlot cattle (Jones et al., 2004). However, this vaccine is no longer commercially available. In a randomized and blinded field trial, Checkley et al. (2005) reported that Fusogard vaccination reduced prevalence of $\mathrm{A}$ or $\mathrm{A}+$ liver abscesses in cattle with a low prevalence $(10 \%)$, but was not effective in cattle with a high prevalence $(30 \%)$ of liver abscesses. Fox et al. (2009) conducted a study to evaluate the efficacy of the 2 commercial vaccines available at the time in natural-fed feedlot cattle. Feedlot cattle $(n=1,307)$ were randomly assigned to 1 of 3 treatments: no vaccine (control) or vaccination with either Fusogard or Centurion and all animals were fed a diet of $73 \%$ steam-flaked corn and $13 \%$ roughage. Cattle were harvested after $238 \mathrm{~d}$ on feed, and the incidence of total liver abscesses and severe liver abscesses $(\mathrm{A}+)$ was relatively high $(56 \%$ and $39 \%$, re- 
spectively). Both vaccines did not affect the incidence of total liver abscesses and severe liver abscesses. It is possible that the lack of vaccination effect may be because of the length of feeding of cattle (i.e., $238 \mathrm{~d}$ ) in the natural production system. Machado et al. (2014) reported on subcutaneous immunization with vaccine formulations containing different combinations of proteins of E. coli, F. necrophorum, and T. pyogenes to prevent puerperal metritis, leading to improved reproduction in dairy cows.

Narayanan et al. (2003) evaluated the efficacy of recombinant leukotoxin of $F$. necrophorum in a mouse model for liver abscesses. The gene encoding the leukotoxin (lktA) in F. necrophorum was cloned, sequenced, and expressed in E. coli (Narayanan et al., 2001). Because of low expression levels, problems associated with purifying full-length recombinant protein, and of the physical instability of the protein, 5 overlapping leukotoxin gene truncations were constructed. Five recombinant polypeptides (BSBSE, SX, GAS, SH, and FINAL) were expressed in E. coli and purified by Ni-affinity chromatography (Narayanan et al., 2001). All polypeptides were immunogenic; 2 polypeptides (BSBSE and $\mathrm{SH}$ ) induced significant protection in mice against $F$. necrophorum infection. The protection was superior to the full-length native leukotoxin or inactivated culture supernatant containing leukotoxoid (Narayanan et al., 2003). However, the efficacy of the recombinant Lkt polypeptides in cattle has not been evaluated. Another antigen of F. necrophorum that has been targeted as a potential candidate for vaccine development is outer membrane proteins, which mediate adhesion of $F$. necrophorum to bovine cells (Kumar et al., 2013). Interestingly, the outer membrane profile of subsp. necrophorum is different from that of the subsp. funduliforme (Kumar et al., 2014). Bacterial adhesion is a critical step in the establishment of infection and disease pathogenesis of many Gram-negative bacterial species (Bavington and Page, 2005). An outer membrane protein of $42.4 \mathrm{kDa}$, which binds with high affinity to the bovine endothelial cells and to which antibodies are present in the sera from liver abscessed cattle has been described (Kumar et al., 2015). A similar protein, called FomA, has been characterized in another species of Fusobacterium, F. nucleatum, a human oral pathogen (Han et al., 2005). A vaccine prepared using FomA of $F$. nucleatum has been shown to prevent oral infections in a mouse model (Liu et al., 2010). Further studies are needed to assess outer membrane protein as a potential vaccine candidate to control liver abscess in feedlot cattle.

\section{SUMMARY AND CONCLUSIONS}

Liver abscesses continue to be of significant economic concern to the feedlot industry. The incidence of total liver abscesses, particularly the severe form $(\mathrm{A}+)$, is greater in Holstein steers raised for beef production and in cull dairy cows than in beef breeds, but reasons are not known. A recent report on isolation of Salmonella enterica in liver abscesses is a novel finding, but the role and the importance need to be investigated. Although tylosin is widely used to control of liver abscesses, the use will be under veterinary oversight beginning of 2017. There is considerable interest in evaluating antibiotic alternatives, such as essential oils and vaccines, to control liver abscesses. Leukotoxin, an exotoxin and an outer membrane protein of Fusobacterium necrophorum have been the target antigens investigated for the development of vaccines. However, an efficacious vaccine has not been developed yet.

\section{LITERATURE CITED}

Aljameel, M. A., M. O. Halima, A. E. El Tigani-Asil, A. S. Abdalla, and M. M. Abdellatif. 2014. Liver abscesses in dromedary camels: Pathological characteristics and aerobic bacterial etiology. Open Vet. J. 4:118-123.

Amachawadi, R. G., and T. G. Nagaraja. 2015. First report of anaerobic isolation of Salmonella enterica from liver abscesses of feedlot cattle. J. Clin. Microbiol. 53:3100-3101.

Amess, J. A., W. O’Neill, C. N. Giollariabhaigh, and J. K. Dytrych. 2007. A six-month audit of the isolation of Fusobacterium necrophorum from patients with sore throat in a district general hospital. Br. J. Biomed. Sci. 64:63-65.

Bavington, C., and C. Page. 2005. Stopping bacterial adhesion: A novel approach to treating infections. Respiration. 72:335-344.

Biberstein, E. L. 1990. Corynebacteria; Actinomyces pyogenes; Rhodococcus equi. In: E. L. Biberstein and Y. C. Zee, editors, Review of veterinary microbiology. Blackwell Scientific, Boston, MA. p. 165.

Bicalho, M. L., V. S. Machado, G. Oikonomou, R. O. Gilbert, and R. C. Bicalho. 2012. Association between virulence factors of Escherichia coli, Fusobacterium necrophorum, and Arcanobacterium pyogenes and uterine diseases of dairy cows. Vet. Microbiol. 157:125-131.

Billington, S. J., B. H. Jost, W. A. Cuevas, K. R. Bright, and J. G. Songer. 1997. The Arcanobacterium (Actinomyces) pyogenes Hemolysis, Pyolysin, is a novel member of the thiol-activated cytolysin family. J. Bacteriol. 179:6100-6106.

Brent, B. E. 1976. Relationship of acidosis to other feedlot ailments. J. Anim. Sci. 43:930-935.

Brink, D. R., S. R. Lowry, R. A. Stock, and J. C. Parrott. 1990. Severity of liver abscesses and efficiency of feed utilization of feedlot cattle. J. Anim. Sci. 68:1201-1207.

Brown, H., R. F. Bing, H. P. Grueter, J. W. McAskill, C. O. Cooley, and R. P. Rathmacher. 1975. Tylosin and chlortetracycline for the prevention of liver abscesses, improved weight gains and feed efficiency in feedlot cattle. J. Anim. Sci. 40:207-213.

Brown, T. R., and T. E. Lawrence. 2010. Association of liver abnormalities with carcass grading performance and value. J. Anim. Sci. 88:4037-4043. 
Bugarel, M., H. C. den Baker, K. K. Nightingale, D. M. BrichtaHarhay, T. S. Edrington, and G. H. Loneragan. 2015. Two draft genome sequences of a new serovar of Salmonella enterica, serovar Lubbock. Genome Announc. 3:e0215.

Calcutt, M. J., M. F. Foecking, T. G. Nagaraja, and G. C. Stewart. 2014. Draft genome sequence of Fusobacterium necrophorum subsp. funduliforme bovine liver abscess isolate B35. Genome Announc. 2:e00412.

Chaudhry, R., R. K. Mahajan, A. Diwan, S. Khan, R. Singhal, D. S. Chandel, and C. Hans. 2003. Unusual presentation of enteric fever: Three cases of splenic and liver abscesses due to Salmonella Typhi and Salmonella Paratyphi A. Trop. Gastroenterol. 24:198-199.

Checkley, S. L., E. D. Janzen, J. R. Campbell, and J. J. McKinnon. 2005. Efficacy of vaccination against Fusobacterium necrophorum infection for control of liver abscesses and footrot in feedlot cattle in western Canada. Can. Vet. J. 46:1002-1007.

Coe, M. L., T. G. Nagaraja, Y. D. Sun, N. Wallace, E. G. Towne, K. E. Kemp, and J. P. Hutcheson. 1999. Effect of virginiamycin on ruminal fermentation in cattle during adaptation to a high concentrate diet and during an induced acidosis. J. Anim. Sci. 77:2259-2268.

Coyle-Dennis, J. E., and L. H. Lauerman. 1979. Correlations between leucocidin production and virulence of two isolates of $\mathrm{Fu}$ sobacterium necrophorum. Am. J. Vet. Res. 40:274-276.

Davies, M. S., W. C. Koers, K. J. Vander Pol, and O. A. Turgeon. 2007. Liver abscess score and carcass characteristics of feedlot cattle. J. Anim. Sci. 85:126-127.

DeHaan, K. A., M. T. Van Koevering, and M. L. Gibson. 1995. The effect of age, background, and gender on feed intake by feedlot cattle In: Proceedings from feed intake by feedlot cattle. Oklahoma State Beef Extension, Stillwater, OK, http://beefextension. com/pages/proceedings95.html. (Accessed 13 December 2015.)

Dirksen, G. U., H. G. Liebich, and E. Meyer. 1985. Adaptive changes of the ruminal mucosa and their functional and clinical significance. Bovine Pract. 20:116-120.

Doré, E., G. Fecteau, P. Hélie, and D. Francoz. 2007. Liver abscesses in Holstein dairy cattle: 18 cases (1992-2003). J. Vet. Intern. Med. 21:853-856.

Duff, G. C., and C. P. McMurphy. 2007. Feeding Holstein steers from start to finish. Vet. Clin. North Am. Food Anim. Pract. 23:281-297.

Elam, C. J. 1976. Acidosis in feedlot cattle: Practical interventions. J. Anim. Sci. 43:898-901.

Elanco Liver-Check Service. 2015. http://www.elanco.us/productsservices/beef/services/quantify-cost-liver-abscesses-feedyardbottom-line.aspx. (Accessed 15 December 2015.)

Elwakeel, E. A., R. G. Amachawadi, A. M. Nour, M. E. Nasser, T. G. Nagaraja, and E. C. Titgemeyer. 2013. In vitro degradation of lysine by ruminal fluid-based fermentations and by Fusobacterium necrophorum. J. Dairy Sci. 96:495-505

Emery, D. L., and J. A. Vaughan. 1986. Generation of immunity against Fusobacterium necrophorum or mice inoculated with extracts containing leukotoxin. Vet. Microbiol. 12:255-268.

Emery, D. L., J. A. Vaughan, B. L. Clark, J. H. Dufty, and D. J. Stewart. 1985. Cultural characteristics and virulence of strains of Fusobacterium necrophorum isolated from the feet of cattle and sheep. Aust. Vet. J. 62:43-46.

Eng, K. S. 2005. Dairy beef production past, present, and future In: Proceedings from managing and marketing quality Holstein steers. Univ. of Minnesota Dairy Extension, Rochester, MN, http://www.extension.umn.edu/agriculture/dairy/beef/\#nutrition. (Accessed 12 December 2015.)
Fell, B.F., M. Kay, E.R. Ørskov, and R. Boyne. 1972. The role of ingested animal hairs and plant spicules in the pathogenesis of rumenitis. Res. Vet. Sci. 13:30-36.

FDA. 2012. Guidance for Industry \# 209. April 13, 2012. The judicious use of medically important antimicrobial drugs in food producing animals. FDA Center for Veterinary Medicine, Rockville, MD.

FDA. 2013. Guidance for Industry \# 213. December 12, 2013. The judicious use of medically important antimicrobial drugs in food producing animals. FDA Center for Veterinary Medicine, Rockville, MD.

Fox, J. T., D. U. Thomson, N. N. Lindberg, and K. Barling. 2009. A comparison of two vaccines to reduce liver abscesses in natural fed cattle. Bovine Pract. 43:168-174.

Gragg, S. E., G. H. Loneragan, M. M. Brashears, T. M. Arthur, J. M. Bosilevac, N. Kalchayanand, R. Wang, J. W. Schmidt, J. C. Brooks, S. D. Shackelford, T. L. Wheeler, T. R. Brown, T. S. Edrington, and D. M. Brichta-Harhay. 2013. Cross-sectional study examining Salmonella enterica carriage in subiliac lymph nodes of cull and feedlot cattle at harvest. Foodborne Pathog. Dis. 10:368-374.

Grohn, Y. T., and M. L. Bruss. 1989. Effect of diseases, production and season on traumatic reticuloperitonitis and ruminal acidosis in dairy cattle. J. Dairy Sci. 73:2355-2363.

Gudmundson, J., O. M. Radostitis, and C. E. Doige. 1980. Pulmonary thromboembolism in cattle due to thrombosis of the posterior vena cava associated with hepatic abscessation. Can. Vet. J. 19:304.

Hall, V., B. I. Duerden, J. T. Magee, H. C. Ryley, and J. S. Brazier. 1997. A comparative study of Fusobacterium necrophorum strains from human and animal sources by phenotypic reactions, pyrolysis mass spectrometry and SDS-PAGE. J. Med. Microbiol. 46:865-871.

Han, Y. W., A. Ikegami, C. Rajanna, H. I. Kawsar, Y. Zhou, M. Li, H. T. Sojar, R. J. Genco, H. K. Kuramitsu, and C. X. Deng. 2005. Identification and characterization of a novel adhesin unique to oral fusobacteria. J. Bacteriol. 187:5330-5340.

Hicks, R. B., F. N. Owens, D. R. Gill, J. W. Oltjen, and R. P. Lake. 1994. Daily dry matter intake by feedlot cattle: Influence of breed and gender. J. Anim. Sci. 68:245-253.

Jensen, R., H. M. Deane, L. J. Cooper, V. A. Miller, and W. R. Graham. 1954. The rumenitis-liver abscess complex in beef cattle. Am. J. Vet. Res. 15:202-216.

Jones, G., H. Jayappa, B. Hunsaker, D. Sweeney, V. Rapp-Gabrielson, T. Wasmoen, T. G. Nagaraja, S. Swingle, and M. Branine. 2004. Efficacy of an Arcanobacterium pyogenes-Fusobacterium necrophorum bacterin toxoid as an aid in the prevention of liver abscesses in feedlot cattle. Bovine Pract. 38:36-44.

Jost, B. H., and S. J. Billington. 2005. Arcanobacterium pyogenes: Molecular pathogenesis of an animal opportunist. Antonie van Leeuwenhoek 88:87-102.

Kanoe, M., Y. Izuchi, and M. Toda. 1978. Isolation of Fusobacterium necrophorum from bovine ruminal lesions. Jpn. J. Vet. Sci. 40:275-281.

Kelly, W. R. 1993. The liver and biliary system. In: K. V.F. Jubb, P. C. Kennedy, and N. Palmer, editors, Pathology of domestic animals. 4th ed. Academic Press, San Diego, CA. p. 370-371.

Kumar, A., E. Gart, T. G. Nagaraja, and S. Narayanan. 2013. Adhesion of Fusobacterium necrophorum to bovine endothelial cells is mediated by outer membrane proteins. Vet. Microbiol. 162:813-818. 
Kumar, A., S. Menon, T. G. Nagaraja, and S. Narayanan. 2015. Identification of an outer membrane protein of Fusobacterium necrophorum subsp. necrophorum that binds with high affinity to bovine endothelial cells. Vet. Microbiol. 176:196-201.

Kumar, A., G. Peterson, T. G. Nagaraja, and S. Narayanan. 2014. Outer membrane proteins of Fusobacterium necrophorum subsp. necrophorum and subsp. funduliforme. J. Basic Microbiol. 54:812-817.

Kuppalli, K., D. Livorsi, N. J. Talati, and M. Osborn. 2012. Lemierre's syndrome due to Fusobacterium necrophorum. Lancet Infect. Dis. 12:808-815.

Langworth, B. F. 1977. Fusobacterium necrophorum: Its characteristics and role as an animal pathogen. Bacteriol. Rev. 41:373-390.

Lechtenberg, K. F., T. G. Nagaraja, H. W. Leipold, and M. M. Chengappa. 1988. Bacteriologic and histologic studies of hepatic abscesses in cattle. Am. J. Vet. Res. 49:58-62.

Lechtenberg, K. F., T. G. Nagaraja, and J. C. Parrot. 1993. The role of Actinomyces pyogenes in liver abscess formation In: Scientific update on Rumensin/Tylan for the professional feedlot consultant. Elanco Animal Health, Greenfield, IN. p. E1-E6.

Lee, C. A., and S. Falkow. 1990. The ability of Salmonella to enter mammalian cells is affected by bacterial growth state. Proc. Natl. Acad. Sci. U. S. A. 87:4304-4308.

Liu, P. F., W. Shi, W. Zhu, J. W. Smith, S. L. Hsieh, R. L. Gallo, and C. M. Huang. 2010. Vaccination targeting surface FomA of Fusobacterium nucleatum against bacterial co-aggregation: Implication for treatment of periodontal infection and halitosis. Vaccine 28:3496-3505.

Ludlam, H., J. Howard, B. Kingston, L. Donachie, J. Foulkes, S. Guha, and M. D. Curran. 2009. Epidemiology of pharyngeal carriage of Fusobacterium necrophorum. J. Med. Microbiol. 58:1264-1265.

Lundeen, T. (Ed.) 2013. Feed additive compendium, The Penton, Inc., Minneapolis, MN.

Maas, J., and P. H. Robinson. 2007. Preparing Holstein steer calves for the feedlot. Vet. Clin. North Am. Food Anim. Pract. 23:269-279.

Machado, V. S., M. L. Bicalho, E. B. Meira Junior, R. Rossi, B. L. Ribeiro, S. Lima, T. Santos, A. Kussler, C. Foditsch, E. K. Ganda, G. Oikonomou, S. H. Cheong, R. O. Gilbert, and R. C. Bicalho. 2014. Subcutaneous immunization with inactivated bacterial components and purified protein of Escherichia coli, Fusobacterium necrophorum, and Trueperella pyogenes prevents puerperal metritis in Holstein dairy cows. PLoS ONE 9:e91734.

McKeith, R. O., G. D. Gray, D. S. Hale, C. R. Kerth, D. B. Griffin, J. W. Savell, C. R. Raines, K. E. Belk, D. R. Woerner, J. D. Tatum, J. L. Igo, D. L. VanOverbeke, G. G. Mafi, T. E. Lawrence, R. J. Delmore, Jr., L. M. Christensen, S. D. Shackleford, D. A. King, T. L. Wheeler, L. R. Meadows, and M. E. O'Connor. 2012. National beef quality audit-2011: Harvest-floor assessments of targeted characteristics that affect quality and value of cattle, carcasses, and byproducts. J. Anim. Sci. 90:5135-5142.

Meyer, N. F., G. E. Erickson, T. J. Klopfenstein, M. A. Greenquist, M. K. Luebbe, P. Williams, and M. A. Engstrom. 2009. Effect of essential oils, tylosin, and monensin on finishing steer performance, carcass characteristics, liver abscesses, ruminal fermentation, and digestibility. J. Anim. Sci. 87:2346-2354.

Nagaraja, T. G. 2000. Liver abscesses in beef cattle: Potential for dairy monitoring? Proc. Am. Assoc. Bovine Pract. 33:65-68.

Nagaraja, T. G. 2013. Arcanobacterium. In: D. S. McVey, M. Kennedy, and M. M. Chengappa, editors, Veterinary microbiology, 3rd ed. Wiley-Blackwell, Ames, IA. p. 203-206.
Nagaraja, T. G., A. B. Beharka, M. M. Chengappa, L. H. Carroll, A. P. Raun, S. B. Laudert, and J. C. Parrott. 1999. Bacterial flora of liver abscesses in feedlot cattle fed tylosin or no tylosin. J. Anim. Sci. 77:973-978.

Nagaraja, T. G., and M. M. Chengappa. 1998. Liver abscesses in feedlot cattle: A review. J. Anim. Sci. 76:287-298.

Nagaraja, T. G., S. B. Laudert, and J. C. Parrott. 1996a. Liver abscesses in feedlot cattle. Part 1. Causes, pathogenesis, pathology and diagnosis. Compend. Contin. Educ. Pract. Vet. 18:S230-S256.

Nagaraja, T. G., S. B. Laudert, and J. C. Parrott. 1996b. Liver abscesses in feedlot cattle. Part 2. Incidence, economic importance and prevention. Compend. Contin. Educ. Pract. Vet. 18:S264-S273.

Nagaraja, T. G., and K. F. Lechtenberg. 2007. Liver abscesses in feedlot cattle. Vet. Clin. Food Anim. 23:351-369.

Nagaraja, T. G., S. K. Narayanan, G. C. Stewart, and M. M. Chengappa. 2005. Fusobacterium necrophorum infections in animals: Pathogenesis and pathogenic mechanisms. Anaerobe 11:239-246.

Narayanan, S.K., M. M. Chengappa, G. C. Stewart, and T. G. Nagaraja. 2003. Immunogenicity and protective effects of truncated recombinant leukotoxin proteins of Fusobacterium necrophorum in mice. Vet. Microbiol. 93:335-347.

Narayanan, S. K., T. G. Nagaraja, M. M. Chengappa, and G. C. Stewart. 2001. Cloning, sequencing, and expression of the leukotoxin gene from Fusobacterium necrophorum. Infect. Immun. 69:5447-5455.

Narayanan, S. K., T. G. Nagaraja, M. M. Chengappa, and G. C. Stewart. 2002. Leukotoxins of Gram-negative bacteria. Vet. Microbiol. 84:337-356.

Narayanan, S. K., T. G. Nagaraja, N. Wallace, J. Staats, M. M. Chengappa, and R. D. Oberst. 1998. Biochemical and ribotypic comparison of Actinomyces pyogenes and A. pyogenes-like isolates from liver abscesses, ruminal wall, and ruminal contents of cattle. Am. J. Vet. Res. 59:271-276.

Nazzaro, F., F. Fratianni, L. De Martino, R. Coppola, and V. De Feo. 2013. Effect of essential oils on pathogenic bacteria. Pharmaceuticals (Ott.) 6:1451-1474.

Plaizier, J. C., D. O. Krause, G. N. Gozho, and B. W. McBride. 2008. Subacute ruminal acidosis in dairy cows: The physiological causes, incidence and consequences. Vet. J. 176:21-31.

Purvis, T. J. 2006. Sarcina ventriculi as a potential cause of abomasal bloat in neonatal calves and the bacterial flora of liver abscesses in dairy cattle. MS Thesis. Kansas State University, Manhattan. p. 1-46.

Qu, F., Z. Fan, E. Cui, W. Zhang, C. Bao, S. Chen, Y. Mao, and D. Zhou. 2013. First report of liver abscess caused by Salmonella enterica serovar Dublin. J. Clin. Microbiol. 51:3140-3142.

Rebhun, W. C., V. T. Rendano, S. G. Dill, J. M. King, and E. G. Pearson. 1980. Caudal vena cava thrombosis in four cattle with acute dyspnea. J. Am. Vet. Med. Assoc. 176:1366-1369.

Reinhardt, C. D., and M.E. Hubbert. 2015. Control of liver abscesses in feedlot cattle: A review. The Prof. Am. Sci. 31:101-108

Rezac, D. J., D. U. Thomson, S. J. Bartle, J.B. Osterstock, F. L. Prouty, and C. D. Reinhardt. 2014a. Prevalence, severity, and relationships of lung lesions, liver abnormalities.

Rezac, D. J., D. U. Thomson, M. G. Siemens, F. L. Prouty, C. D. Reinhardt, and S. J. Bartle. 2014b. A survey of gross pathologic conditions in cull cows at slaughter in the Great Lakes region of the United States. J. Dairy Sci. 97:4227-4235.

Ribeiro, M .G., R.M. Risseti, C. A. Bolanos, K. A. Caffaro, A. C. de Morais, G. H. Lara, T. O. Zamprogna, A. C. Paes, F. J. Listoni, and M. M. Franco. 2015. Trueperella pyogenes multispecies infections in domestic animals: A retrospective study of 144 cases (2002 to 2012). Vet. Q. 35:82-87. 
Rumbaugh, G. E., B. P. Smith, and G. P. Carlson. 1978. Internal abdominal abscesses in the horse: A study of 25 cases. J. Am. Vet. Med. Assoc. 172:304-309.

Russell, J. B. 2006. Factors affecting lysine degradation by ruminal fusobacteria. FEMS Microbiol. Ecol. 56:18-24.

Saginala, S., T. G. Nagaraja, K .F. Lechtenberg, M. M. Chengappa, K. E. Kemp, and P. M. Hine. 1997. Effect of Fusobacterium necrophorum leukotoxoid vaccine on susceptibility to experimentally induced liver abscesses. J. Anim. Sci. 75:1160-1166.

Santa Rosa, J., E. H. Johnson, F. S. F. Alves, and L. F. L. Santos. 1989. A retrospective study of hepatic abscesses in Goats: Pathological and microbiological findings. Br. Vet. J. 145:73-76.

Scanlan, C. M., and T. L. Hathock. 1983. Bovine rumenitis-liver abscess complex: A bacteriological review. Cornell Vet. 73:288-297.

Schiemann, D. A., and S. R. Shope. 1991. Anaerobic growth of Salmonella Typhimurium results in increased uptake by Henle 407 epithelial and mouse peritoneal cells in vitro and repression of a major outer membrane protein. Infect. Immun. 59:437-440.

Sellon, D. C., K. Spaulding, B. A. Breuhaus, L. Katz, and R. Mealey. 2000. Hepatic abscesses in three horses. J. Am. Vet. Med. Assoc. 216:882-887.

Shinjo, T., T. Fujisawa, and T. Mitsuoka. 1991. Proposal of two subspecies of Fusobacterium necrophorum (Flugge) Moore and Holdeman: Fusobacterium necrophorum subsp. necrophorum subsp. nov., nom. rev. (ex Flugge 1886), and Fusobacterium necrophorum subsp. funduliforme subsp. nov., nom. rev. (ex Hallé 1898). Int. J. Syst. Bacteriol. 41:395-397.

Smith, H. A. 1944. Ulcerative lesions of the bovine rumen and their possible relation to hepatic abscesses. Am. J. Vet. Res. 5:234-242.

Tadepalli, S., G. C. Stewart, T. G. Nagaraja, and S. K. Narayanan. 2008. Human Fusobacterium necrophorum strains have a leukotoxin gene and exhibit leukotoxic activity. J. Med. Microbiol. 57:225-231.

Tadepalli, S., S. K. Narayanan, G. C. Stewart, M. M. Chengappa, and T. G. Nagaraja. 2009. Fusobacterium necrophorum: A ruminal bacterium that invades liver to cause abscesses in cattle. Anaerobe 15:36-43.

Tan, Z. L., T. G. Nagaraja, and M. M. Chengappa. 1992. Factors affecting the leukotoxin activity of Fusobacterium necrophorum. Vet. Microbiol. 32:15-28.

Tan, Z. L., T. G. Nagaraja, and M. M. Chengappa. 1994. Selective enumeration of Fusobacterium necrophorum from the bovine rumen. Appl. Environ. Microbiol. 60:1387-1389.
Tan, Z. L., T. G. Nagaraja, and M. M. Chengappa. 1996. Fusobacterium necrophorum infections: Virulence factors, pathogenic mechanism and control measures. Vet. Res. Commun. 20:113-140.

Tehrani, A., J. Javanbakht, M. A. M. Hassan, M. Zamani, M. Rajabian, H. Akbari, and R. Shafel. 2012. Histopathological and bacteriological study on hepatic abscesses of Herrik sheep. J. Med. Microb. Diagn. 1:4.

USDA. 2015. Livestock slaughter 2014 summary, April 2015. Natl. Agric. Stat. Serv., Washington, DC. p. 1-68.

Vogel, G. J., and J. C. Parrott. 1994. Mortality survey in feed yards: The incidence of death from digestive, respiratory and other causes in feed yards on the Great Plains. Compend. Contin. Educ. Pract. Vet. 16:227-234.

Wieser, M. F., T. R. Preston, A. Macdearmid, and A. C. Rowland. 1966. Intensive beef production 8 . The effect of chlortetracycline on growth, feed utilization and incidence of liver abscesses in barley beef cattle. Anim. Prod. 8:411-423.

Wileman, B. W., D. U. Thomson, C. D. Reinhardt, and D. G. Renter. 2009. Analysis of modern technologies commonly used in beef cattle production: Conventional beef production versus nonconventional production using meta-analysis. J. Anim. Sci. 87:3418-3426.

Yamamoto, N., and M. L. Droffner. 1985. Mechanisms determining aerobic or anaerobic growth in the facultative anaerobe Salmonella typhimurium. Proc. Natl. Acad. Sci. USA 82:2077-2081.

Yassin, A. F., H. Hupfer, C. Siering, and P. Schumann. 2011. Comparative chemotoxonomic and phylogenetic studies on the genus Arcanobacterium Collins et al. 1982 emend. Lehnen et al. 2006: Proposal for Trueperella gen. nov. and emended description of the genus Arcanobacterium. Int. J. Syst. Evol. Microbiol. 61:1265-1274.

Zhang, F., T. G. Nagaraja, D. George, and G. C. Stewart. 2006. The two major subspecies of Fusobacterium necrophorum have distinct leukotoxin operon promoter regions. Vet. Microbiol. 112:73-78.

Zicker, S. C., W. D. Wilson, and I. Medearis. 1990. Differentiation between intra-abdominal neoplasms and abscesses in horses using clinical and laboratory data: 40 cases (1978-1988). J. Am. Vet. Med. Assoc. 196:1130-1132.

Zou, W., W. J. Lin, S. L. Foley, C. H. Chen, R. Nayak, and J. J. Chen. 2010. Evaluation of pulsed-field gel electrophoresis profiles for identification of Salmonella serotypes. J. Clin. Microbiol. 48:3122-3126. 